\title{
Analisis Rasio Keuangan untuk Menilai Kinerja Keuangan KSPPS Khairu Ummah Leuwiliang Periode 2017-2020
}

\author{
Ilma Yuliyastri' ${ }^{1}$, Suyud Arif ${ }^{2}$, Abrista Devi ${ }^{3}$ \\ 1,2,3Ekonomi Syariah Universitas Ibn Khaldun Bogor \\ ilmayuliyastri@gmail.com¹, suyudarif@fai.uika-bogor.ac.id², \\ abristasmart@gmail.com ${ }^{3}$
}

\begin{abstract}
An important factor for cooperative institutions is financial performance. The company's financial performance level can be evaluated by analyzing past financial statements. The purpose of the research is to determine the financial performance of KSPPS Khairu Ummah for the period 2017-2020 based on the standard decree of the Minister of Cooperatives and Small and Medium Enterprises No.06/Per/M/KUKM/V/2006 on Health Assessment Standards. And based on the Ministry of Cooperatives and Small and Medium Enterprises of the Republic of Indonesia Number: 7/Per/Dep.6/IV/2016 on Guidelines for Health Assessment of Cooperatives Save Borrowing and Sharia Financing and Unit Save Borrowing And Sharia Financing Cooperatives. The method used is quantitative method. The results showed that the financial performance of KSPPS Khairu Ummah in terms of liquidity, solvency, activity and profitability is still below the standard decree of the Minister of Cooperatives and SMEs No.06/Per/M/KUKM/V/2006, and the results of research in terms of capital, efficiency, liquidity, independence and growth has been included in the standard health assessment and the Ministry of Cooperatives and Small and Medium Enterprises of the Republic of Indonesia Number: 7/Per/Dep.6/IV/2016.
\end{abstract}

Keywords: Financial performance, Financial ratio

\section{ABSTRAK}

Faktor penting bagi lembaga koperasi adalah kinerja keuangan. Tingkat kinerja keuangan perusahaan dapat dievaluasi dengan menganalisis laporan keuangan masa lalu. Tujuan dari penelitian ini adalah untuk mengetahui kinerja keuangan KSPPS Khairu Ummah periode 2017-2020 berdasarkan Standar Keputusan Menteri Koperasi dan Usaha Kecil dan Menengah No.06/Per/M/KUKM/V/2006 tentang Standar Penilaian Kesehatan. Dan berdasarkan Kementrian Koperasi dan Usaha Kecil dan Menengah Republik Indonesia Nomor : 7/Per/Dep.6/IV/2016 tentang Pedoman Penilaian Kesehatan Koperasi Simpan Pinjam dan Pembiayaan Syariah dan Unit Simpan Pinjam Dan Koperasi Pembiayaan Syariah . Metode yang digunakan adalah metode kuantitatif. Hasil penelitian menunjukkan bahwa kinerja keuangan KSPPS Khairu Ummah dari segi likuiditas, solvabilitas, aktivitas dan profitabilitas masih di bawah standar Keputusan Menteri Koperasi dan UKM No.06/Per/M/KUKM/V/2006, dan hasil penelitian dari segi permodalan, efisiensi, likuiditas, kemandirian dan pertumbuhan telah dimasukkan dalam standar penilaian kesehatan dan Kementerian Koperasi dan Usaha Kecil Menengah Republik Indonesia Nomor : 7/Per/Dep.6/IV/ 2016.

Kata kunci: Kinerja keuangan, Rasio keuangan 


\section{Vol 4 No 1 (2021) 52-62 P-ISSN 2620-295 E-ISSN 2747-0490 DOI: $1047467 /$ elmal.v4i1.522}

\section{PENDAHULUAN}

Di era globalisasi ini, dunia bisnis berkembang pesat dan semakin banyak bermunculan perusahaan-perusahaan baru. Akibatnya, hal ini memungkinkan perusahaan untuk mengoperasikan roda organisasi perusahaan secara lebih efisien. Secara umum, tujuan dari sebuah perusahaan adalah untuk mendapatkan keuntungan. Laba adalah hasil yang menguntungkan dari usaha perusahaan dalam jangka waktu tertentu. Dengan keuntungan ini, perusahaan dapat menggunakannya untuk memberikan tambahan pembiayaan bagi bisnis, dan yang terpenting, sebagai alat untuk mempertahankan kelangsungan hidup perusahaan. (Rhamadana, 2016)

Perkembangan dan pertumbuhan koperasi belum sepenuhnya menunjukkan bentuk dan perannya, sampai saat ini sektor swasta masih mendominasi perekonomian Indonesia, dan kontribusi koperasi terhadap perekonomian Indonesia adalah baris terakhir. Oleh karena itu, untuk menggerakkan dan memperluas perekonomian rakyat, koperasi harus berusaha semaksimal mungkin untuk mencapai kinerja operasi yang kuat dan efisien. Karena hanya dengan cara ini koperasi dapat menjadikan ekonomi kerakyatan sebagai tumpuan kekuatan dan ketahanan ekonomi nasional. (Baswir dalam Tolong, 2020)

Koperasi Syariah merupakan salah satu solusi untuk mengelola keuangan syariah bagi umat Islam sesuai dengan ajaran Islam, karena kegiatan, tujuan dan prinsip bisnisnya berdasarkan Al-Qur'an dan Hadits. (Ghulam, 2016)

Koperasi Simpan Pinjam Pembiayaan Syariah (KSPPS) Khairu Ummah merupakan salah satu lembaga keuangan syariah non bank berbadan hukum koperasi di Kabupaten Bogor. Yang didirikan pada tanggal 24 Agustus 1994. Koperasi Syariah Khairu Ummah terpilih sebagai koperasi BERPRESTASI TAHUN 2019 setelah sebelumnya juga menerima penghargaan sebagai KOPERASI UNGGULAN TINGKAT KABUPATEN BOGOR TAHUN 2019.

Koperasi adalah badan usaha yang sesuai dengan demokrasi ekonomi, karena dalam demokrasi ekonomi terdapat unsur-unsur usaha koperasi. Sebagai kriteria umum untuk memahami kinerja keuangan, laporan keuangan yang dikeluarkan oleh koperasi diperlukan untuk melihat keberhasilan dan permasalahan koperasi dalam pengelolaan keuangan. Pada dasarnya, laporan keuangan adalah daftar keuangan yang berhubungan langsung dengan status keuangan dan operasi keuangan, yang keduanya memberikan informasi tentang status keuangan koperasi. Dalam pengukuran status keuangan, unsurunsur yang berhubungan langsung adalah aset, kewajiban dan ekuitas. Sedangkan faktor yang berhubungan dengan pengukuran operasi keuangan adalah pendapatan dan biaya yang tercermin dalam laba/rugi bersih koperasi. Analisis laporan keuangan mencakup penerapan berbagai alat dan teknik analisis terhadap laporan dan data keuangan untuk memperoleh metrik dan hubungan yang bermakna dan berguna dalam proses pengambilan keputusan.Oleh karena itu, tujuan analisis laporan keuangan adalah mengubah data menjadi informasi. Misalnya, sebagai alat peramalan kondisi dan kinerja keuangan masa depan. Berbagai macam teknik yang umum digunakan untuk analisis, salah satunya adalah analisis rasio. (Tolong, 2021) 


\section{Vol 4 No 1 (2021) 52-62 P-ISSN 2620-295 E-ISSN 2747-0490 DOI: $1047467 /$ elmal.v4i1.522}

Terdapat penelitian Analisis Kinerja Keuangan Koperasi antara lain (Suwarto, 2018) dengan judul "Financial Ratio Analysis To Assess Financial Performance Of Cooperatives" Hasil penelitian menunjukkan bahwa kinerja keuangan PT KSPPS BMT ArRahmah Mitra Insani dalam hal profitabilitas, likuiditas dan solvabilitas secara umum masih di bawah standar Menteri Koperasi dan Koperasi UKM RI No.06 /Per/M.KUKM/V/2006 dengan kriteria buruk dan kurang baik. Kemudian, (Eindrias, 2017) dengan judul "Analisa Tingkat Kesehatan Koperasi Simpan Pinjam Berdasarkan Peraturan Nomor: 06/Per/Dep.6/IV/2016" Penilaian kesehatan koperasi simpan pinjam bahagia dilihat dari aspek permodalan, aspek kualitas aktiva produktif, aspek manajemen, aspek efisiensi, aspek likuiditas, aspek kemandirian dan pertumbuhan, serta aspek jatidiri koperasi dilihat dari hasil skor setiap aspek dapat dikategorikan cukup baik untuk beberapa aspek, namun ada beberapa aspek dengan skor masih cukup rendah.

Oleh karena itu pengukuran dan analisis kinerja koperasi sangatlah penting, salah satunya dengan analisa kinerja keuangan agar dapat diketahui apakah kinerja dan proses yang terjadi di dalam aktivitas koperasi sudah berjalan efektif dan efisien, sehingga mampu menempatkan koperasi sebagai lembaga keuangan yang tidak hanya mampu berperan penting dalam peningkatan taraf ekonomi dan skill anggotanya, namun dapat menunjukkan peran strategis dalam memberdayakan masyarakat yang ada di wilayahnya.

\section{METODE PENELITIAN}

Metode penelitian pada dasarnya merupakan cara ilmiah untuk mendapatkan data dengan tujuan dan kegunaan tertentu (Sugiyono, 2014). Jenis penelitian ini adalah penelitian kuantitatif, dimana dalam penelitian ini menggambarkan dan menjelaskan penilaian kinerja keuangan KSPPS Khairu Ummah Leuwiliang No.102, Jl. Raya Leuwiliang, Kec. Leuwiliang, Bogor, Jawa Barat 16640 dengan menggunakan laporan keuangan sebagai dasar penilaian kinerja keuangan.

Jenis data dalam penelitian ini menggunakan data sekunder yang banyak disediakan di instansi atau lembaga-lembaga milik pemerintah atau swasta. (Martono, 2011)

Berdasarkan Keputusan Menteri Negara Koperasi dan UKM No.06/Per/M/KUKM/V/2006, cara menilai kinerja keuangan dengan Analisis rasio yang terbagi dari empat kelompok sebagai berikut:

1. Rasio likuiditas Rasio lancar (current ratio), current ratio merupakan rasio untuk mengukur kemampuan koperasi dalam membayar kewajiban jangka pendek atau utang yang segera jatuh tempo dengan aktiva lancar yang tersedia. Dihitung dengan cara membagi aktiva lancar dengan kewajiban lancar dengan rumus sebagai berikut ;

$$
\text { current ratio }=\frac{\text { aktiva lancar }}{\text { hutang lancar }} \quad \mathrm{X} 100 \%
$$

Kriteria current ratio yang digunakan yaitu: 
Vol 4 No 1 (2021) 52-62 P-ISSN 2620-295 E-ISSN 2747-0490

DOI: 1047467/elmal.v4i1.522

Sangat baik $=200 \%-250 \%$

Baik $=175 \%-<200 \%$

Cukup baik $=150 \%-<175 \%$

Kurang baik $=125 \%-<150$ Buruk $=125 \%$

2. Rasio solvabilitas Debt to Total Assets Ratio dan Debt to Total Equity Ratio.

a. Total Debt to Total Assets Ratio merupakan rasio yang digunakan untuk mengukur persentase besarnya dana yang berasal dari liabilitas(hutang). Dihitung dengan cara membagi total hutang dengan total aktiva.

DtAR = $\frac{\text { Total Hutang }}{\text { Total Aktiva }} \times 100 \%$

Kriteria debt to total asset ratio yang digunakan yaitu:

Sangat baik $=<40 \%$

Baik $=40 \%-<50 \%$

Cukup baik $=50 \%-<60 \%$

Kurang baik $=60-<80 \%$

Buruk $=>80 \%$

b. Debt to Total Equity Ratio merupakan rasio yang digunakan untuk mengetahui jumlah dana yang disediakan peminjam (kreditor) dengan pemilik perusahaan. Rasio ini Dihitung dengan cara membagi total hutang dengan modal sendiri

\section{DtER $=$ Total Hutang $\quad$ X100\% \\ Modal Sendiri}

Kriteria Debt to Total Equity Ratio yang digunakan yaitu:

Sangat baik $=<70 \%$

Baik $=>70 \%-100 \%$

Cukup baik $=>100 \%-150 \%$

Kurang baik $=>150 \%-200 \%$

Tidak baik $=>200 \%$

3. Rasio Aktivitas, Receivable Turn Over dan Total Asset Turn Over.

a. Receivable Turn Over, rasio ini mengukur efektivitas pegelolaan piutang. Semakin tinggi tingkat perputaran maka semakin efekti pengelolaan piutangnya. Rasio in dihitung dengan cara membagi penjualan dengan piutang rata-rata

\section{Receivable Turn Over $=\quad$ Total Hutang $\quad \mathrm{X} 100 \%$}

Kriteria Debt to Total Equity Ratio yang digunakan yaitu:

Baik sekali $=>12$ 
Vol 4 No 1 (2021) 52-62 P-ISSN 2620-295 E-ISSN 2747-0490

DOI: 1047467/elmal.v4i1.522

Baik $=10 \%-<12 \%$

Cukup baik $=8 \%-<10 \%$

Kurang baik $=6 \%-<8 \%$

Tidak baik $=<6 \%$

b. Total Asset Turn Over, rasio ini ukuran efektivitas pemanfaat aset dalam menghasilkan penjualan. Semakin tinggi tingkat perputarannya maka semakin efektif perusahaan memanfaatkan asetnya. Rasio ini dihitung dengan cara membagi penjualan dengan rata-rata total aset.

Total Asset Turn Over = Total Hutang

$\mathrm{X} 100 \%$

Rata-rata total aset

Kriteria Debt to Total Equity Ratio yang digunakan yaitu:

Baik sekali $=>3,5$ kali

Baik $=2,5$ kali $-3,5$ kali

Cukup Baik = 1,5 kali $-2,5$ kali

kurang baik $=1$ kali- 1,5 kali

Tidak baik $=<1$ kali

4. Rasio Profitabilitas, Return On Assets, Return On Equity, Net Profit Margin.

a. Return On Assets merupakan kemampuan perusahaan dalam menghasilkan laba dengan semua aset yang dimiliki perusahaan. Rasio ini dihitung dengan cara membagi sisa hasil usaha dengan asset.

\section{Return On Assets $=\quad$ SHU \\ Asset}

Kriteria ROA yang digunakan yaitu:

Sangat baik $=>10 \%$

Baik $=7 \%-<10 \%$

Cukup baik $=3 \%-<7 \%$

Kurang baik $=1 \%-<3 \%$

Tidak baik $=<1 \%$

b. Return On Equity merupakan rasio untuk mengukur laba bersih sesudah pajak dengan modal sendiri. Rasio ini dihitung dengan cara membagi sisa hasil usaha dengan modal sendiri.

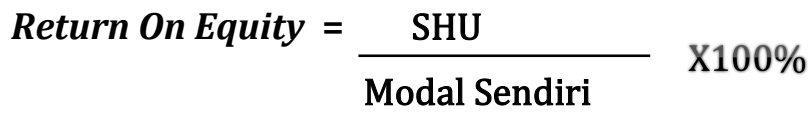

Kriteria $R O E$ yang digunakan yaitu:

Sangat baik $=21 \%$

Baik $=15 \%-<21 \%$

Cukup baik $=10 \%-<15 \%$

Kurang baik $=3 \%-<10 \%$ 


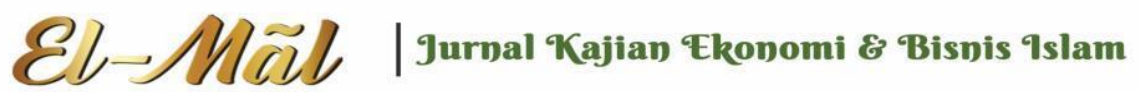

Vol 4 No 1 (2021) 52-62 P-ISSN 2620-295 E-ISSN 2747-0490

DOI: 1047467/elmal.v4i1.522

Buruk $\quad=<3 \%$

c. Net Profit Margin rasio ini digunakan untuk mengukur kemampuan perusahaan dalam mendapatkan laba bersih dari penjualan. Rasio ini dihitung dengan cara sisa hasil usaha dengan pendapatan

$$
\text { Net Profit Margin }=\frac{\text { SHU }}{\text { Pendapatan }} \times 100 \%
$$

Kriteria NPM yang digunakan yaitu:

Sangat baik $=>15 \%$

Baik $\quad=10 \%-<15 \%$

Cukup baik $=5 \%-<10 \%$

Kurang baik $=1 \%-<5 \%$

Buruk $\quad=<1 \%$

Berdasarkan Kementerian Koperasi dan Usaha Kecil dan Menengah Republik Indonesia Nomor: 7/Per/Dep.6/IV/2016

1. Rasio permodalan, rasio modal sendiri terhadap total aset dan rasio kecukupan modal (CAR).

a. Rasio modal sendiri terhadap total aset dihitung dengan cara membagi modal sendiri dengan total aset.

\section{Rasio Modal Sendiri $=\frac{\text { Modal Sendiri }}{\text { Total Aset }} \quad \mathrm{X} 100 \%$}

Kriteria rasio modal sendiri terhadap aset yang digunakan yaitu:

Sehat $=3,76-5,0$

Cukup Sehat $=2,51-3,75$

Kurang Sehat $=1,26-2,50$

Tidak Sehat $=0-1,25$

b. Rasio kecukupan modal (CAR) dihitung dengan cara membagi modal tertimbang dengan ATMR

$$
\text { CAR }=\frac{\text { Modal Tertimbang }}{\text { ATMR }} \quad \mathrm{X} 100 \%
$$

Kriteria CAR yang digunakan yaitu:

Sehat $=5,00$

Cukup Sehat $=3,75$

Kurang Sehat $=2,50$

Tidak Sehat $=1,25$

2. Penilaian efisiensi dilihat dari aspek rasio aktiva terhadap total aset dihitung dengan cara membagi aktiva tetap dengan total aset.

\section{Rasio aktiva tetap terhadap aset $=$ Aktiva tetap $\mathrm{X} 100 \%$ \\ Total aset}

Kriteria rasio aktiva tetap terhadap total aset yang digunakan yaitu:

Baik = 1

Cukup Baik = 2 


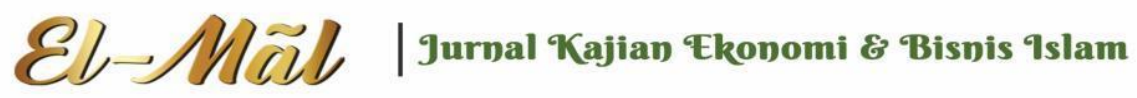

Vol 4 No 1 (2021) 52-62 P-ISSN 2620-295 E-ISSN 2747-0490

DOI: 1047467/elmal.v4i1.522

Kurang Baik $=3$

Tidak Baik $=4$

3. Likuiditas dilihat dari rasio kas dihitung dengan cara membagi kas+bank dengan kewajiban lancar.

\section{Rasio kas $=$ Kas+bank $\quad \mathrm{X} 100 \%$ Kewajiban lancar}

Kriteria rasio kas yang digunakan yaitu:

Liquid $=2,5$

Cukup Liquid $=5$

Kurang Liquid $=7,5$

Tidak Liquid $=10$

4. Kemandirian dan pertumbuhan aset dilihat dari rentabilitas aset, dihitung dengan cara membagi SHU Sebelum pajak dengan total aset.

\section{Rentabilitas Aset $=\frac{\text { SHU sebelum pajak }}{\text { Total aset }} \quad \mathrm{X} 100 \%$}

Kriteria rentabilitas aset yang digunakan yaitu:

Tinggi $=3,00$

Cukup $=2,25$

Kurang $=1,50$

Rendah $=0,75$

\section{HASIL DAN PEMBAHASAN}

Berikut merupakan hasil dari perhitungan analisis rasio keuangan Keputusan Menteri Negara Koperasi dan UKM No.06/Per/M/KUKM/V/2006.

\begin{tabular}{|c|c|c|c|c|}
\hline Rasio & $\mathbf{2 0 1 7}$ & $\mathbf{2 0 1 8}$ & $\mathbf{2 0 1 9}$ & $\mathbf{2 0 2 0}$ \\
\hline Current Ratio & $138,92 \%$ & $126,42 \%$ & $104,34 \%$ & $114,50 \%$ \\
\hline DtAR & $59,95 \%$ & $62,06 \%$ & $64,89 \%$ & $61,77 \%$ \\
\hline DtER & $643 \%$ & $702 \%$ & $673 \%$ & $627 \%$ \\
\hline $\begin{array}{c}\text { Receivable Turn } \\
\text { Over }\end{array}$ & $26 \%$ & $22 \%$ & $22 \%$ & $19 \%$ \\
\hline Aset Turn Over & $0,11 \mathrm{Kali}$ & $0,09 \mathrm{Kali}$ & 0,09 Kali & 0,08 Kali \\
\hline NPM & $12,05 \%$ & $13,13 \%$ & $12,05 \%$ & $7,35 \%$ \\
\hline ROA & $1,32 \%$ & $1,17 \%$ & $1,13 \%$ & $0,58 \%$ \\
\hline ROE & $14,14 \%$ & $13,28 \%$ & $11,71 \%$ & $5,91 \%$ \\
\hline
\end{tabular}

1. Dari hasil analisis rasio lancar (Current Ratio) di atas selama kurun waktu 2017-2018 bahwa kinerja keuangan KSPPS Khairu Ummah masih berada di bawah standar nilai yang ditetapkan. Dan pada tahun 2019-2020 KSPPS mengalami penurunan yang lebih di tahun sebelumnya. Dikarenakan adanya pandemi Covid-19. Hal ini dikarenakan 


\section{Vol 4 No 1 (2021) 52-62 P-ISSN 2620-295 E-ISSN 2747-0490 DOI: $1047467 /$ elmal.v4i1.522}

jumlah hutang lancar yang dimiliki koperasi lebih besar dibanding aset lancar. Sehingga aset koperasi belum cukup likuid dalam membayar hutang jangka pendeknya

2. Dari hasil analisis DtAR di atas selama kurun waktu 2017-2018 menunjukan bahwa kinerja keuangan KSPPS Khairu Ummah berada di penilaian kurang baik yang ditetapkan. Dan di tahun 2019-2020 mengalami kenaikan meskipun $\leq 2 \%$ dikarenakan adanya pandemi Covid-19 jadi penurunan rasio ini menunjukan bahwa semakin rendah pendanaan KSPPS yang bersumber dari hutang sehingga risiko keuangan bisa lebih berkurang. Pada umumnya kreditur dan investor itu lebih menyukai perusahaan dengan nilai rasio total hutang terhadap total aset yang lebih rendah karena akan meminimalisir risiko keuangan yang mungkin terjadi.

3. Dari hasil nilai DtER di atas selama kurun waktu 2017-2018 menunjukan bahwa kinerja keuangan KSPPS Khairu Ummah masih berada di bawah standar nilai yang ditetapkan. Pada tahun 2019-2020 mengalami penurunan tetapi masih berada di bawah standar nilai yang ditetapkan. Nilai $D t E R$ yang tinggi ini disebabkan karena dari tahun ke tahun jumlah modal sendiri koperasi selalu lebih kecil dari jumlah hutang yang dimiliki koperasi. Oleh karena itu, porsi modal sendiri yang dimiliki koperasi belum mampu memberikan kontribusi atau bagian yang cukup dalam melunasi hutang-hutangnya.

4. Dari hasil analisis Receivable Turn Over selama kurun waktu 2017-2018 kinerja keuangan KSPPS Khairu Ummah sangat memenuhi standar yang telah di tetapkan. Begitupun tahun 2019-2020. Jika penjualan yang terjadi secara kredit kepada nasabah. Nasabah diharuskan untuk membayar barang dalam Term of Payment. Jadi nasabah di KSPPS mengambil barang di KSPPS dan nasabah membayar dengan tepat waktu. Karena semakin tinggi perputaran pengelolaan piutang maka akan semakin efektif.

5. Dari hasil analisis Asset Turn Over selama kurun waktu 2017-2018 kinerja keuangan KSPPS Khairu Ummah masih berada di bawah standar yang telah di tetapkan. Begitupun di tahun 2019-2020 bahkan lebih menurun. Jika rasio yang dihasilkan rendah, itu berarti ada tidak beres dengan aset dalam penjualan atau pendapatan. KSPPS mengalami tingginya penjualan yang tidak diimbangi dengan meningkatnya pelanggan. Karena semakin tinggi tingkat perputarannya maka semakin efektif KSPPS memanfaatkan asetnya.

6. Dari hasil analisis NPM menunjukan bahwa selama kurun waktu 2017-2019 kinerja keuangan KSPPS Khairu Ummah sudah memenuhi standar yang telah ditetapkan. Di tahun 2020 mengalami penurunan meskipun masih memenuhi standar yang ditetapkan. Mengalami penurunan menandakan bahwa penurunan kemampuan KSPPS dalam menghasilkan laba atau keuntungan di tahun 2020 disertai dengan adanya penurunan pendapatan untuk memenuhi tingkat biaya tertentu. Karena rasio NPM yang rendah juga dapat mengindikasikan ketidakefisienan dari manajemen KSPPS.

7. Dari hasil analisis ROA menunjukan selama kurun waktu 2017-2018 kinerja keuangan KSPPS Khairu Ummah masih di bawah standar yang telah ditetapkan. Dan di tahun 2019-2020 KSPPS mengalami penurunan lebih. Rasio ROA yang mengalami penurunan menunjukan kemampuan KSPPS untuk menghasilkan laba bersih berdasarkan jumlah aset perusahaan juga mengalami penurunan dan menunjukan adanya penurunan 


\section{Vol 4 No 1 (2021) 52-62 P-ISSN 2620-295 E-ISSN 2747-0490 DOI: $1047467 /$ elmal.v4i1.522}

efisiensi pada manajemen perusahan, koperasi ini dalam menghasilkan $R O A$ belum rentabel.

8. Dari hasil analisis ROE di atas menunjukan bahwa selama kurun waktu 2017-2019 kinerja keuangan KSPPS Khairu Ummah masih berada di bawah standar yang telah ditetapkan. Namun, pada tahun 2020 mengalami penurunan yang banyak karena masa pandemi Covid-19. Rasio ROE yang mengalami penurunan karena target penjualan tidak tercapai kinerja perusahaan yang tidak optimal akan membuat perusahaan sulit untuk meraih laba atau keuntungan. Karena semakin tinggi rasio akan semakin baik. Artinya posisi KSPPS semakin kuat.

Berikut merupakan hasil dari perhitungan analisis rasio keuangan

TABEL 3.2

Hasil Perhitungan Peraturan Deputi Bidang Pengawasan Kementerian KUKM Republik Indonesia Nomor: 7 /Per/Dep.6/IV/2016.

\begin{tabular}{|c|c|c|c|c|}
\hline Rasio & $\mathbf{2 0 1 7}$ & $\mathbf{2 0 1 8}$ & $\mathbf{2 0 1 9}$ & $\mathbf{2 0 2 0}$ \\
\hline $\begin{array}{c}\text { Modal Sendiri } \\
\text { terhadap Total Aset }\end{array}$ & 2,50 & 2,50 & 2,50 & 2,50 \\
\hline CAR & 5,00 & 5,00 & 5,00 & 5,00 \\
\hline $\begin{array}{c}\text { Aktiva Tetap } \\
\text { terhadap total aset }\end{array}$ & 4 & 3 & 3 & 3 \\
\hline Rasio Kas & 7,5 & 7,5 & 7,5 & 7,5 \\
\hline Rentabilitas Aset & 0,75 & 0,75 & 0,75 & 0,75 \\
\hline
\end{tabular}

1. Dari hasil analisis rasio modal sendiri terhadap total aset menunjukan bahwa selama kurun waktu 2017-2018 kinerja keuangan KSPPS Khairu Ummah masih berada di kategori kurang sehat. Tahun 2019-2020 mengalami kenaikan yang tidak baik untuk KSPPS. Rasio modal sendiri terhadap total aset dikarenakan berkurangnya nasabah dalam melakukan simpanan pokok, simpanan wajib, dan simpanan penyertaan. Dikarenakan adanya pandemi Covid-19 yang mempengaruhi perekonomian masyarakat.

2. Dari hasil analisis CAR menunjukan bahwa selama kurun waktu 2017-2018 kinerja keuangan KSPPS Khairu Ummah dikatakan cukup sehat, dan di tahun 2018-2020 juga dikatakan cukup sehat. Sehatnya CAR dipengaruhi oleh karena banyaknya pembiayaan nasabah dan diimbangi dengan nasabah membayar dengan tepat waktu. Sehingga perputaran keuangan stabil.

3. Dari hasil analisis aktiva tetap terhadap total asset menunjukan bahwa selama kurun waktu 2017-2018 masuk dalam kategori cukup baik. Dan di tahun 2019-2020 mengalami penurunan tetapi masih dalam keadaan baik. Rasio ini mengukur kemampuan perusahaan dalam menjalankan aktivitas penjualannya dari seluruh aktiva yang dimilikinya. 


\section{Vol 4 No 1 (2021) 52-62 P-ISSN 2620-295 E-ISSN 2747-0490 DOI: $1047467 /$ elmal.v4i1.522}

4. Dari hasil analisis rasio kas menunjukan bahwa selama kurun waktu 2017-2018 kinerja keuangan KSPPS Khairu dikatakan cukup likuid. Dan pada pandemi Covid-19 rasio kas mengalami kenaikan yang lebih baik dari tahun sebelumnya. Kenaikan rasio kas ini di pengaruhi oleh, KSPPS tersebut banyak menyimpan simpanan penempatan ke bank lain. Dan kas KSPPS tersebut makin tahun makin besar.

5. Dari hasil analisis rentabilitas aset menunjukan bahwa selama kurun waktu 2017-2018 kinerja keuangan KSPPS Khairu Ummah dikatageri rendah. Begitupun di masa pandemi Covid-19 pada tahun 2019 mengalami penurunan yang membuat KSPPS dalam kategori rendah. Mengalami penurunan karena target penjualan tidak tercapai kinerja perusahaan yang tidak optimal akan membuat perusahaan sulit untuk meraih laba atau keuntungan.

\section{KESIMPULAN}

Kesimpulan dari hasil analisis diatas berdasarkan analisis kinerja keuangan KSPPS Khairu Ummah selama empat tahun 2017 sampai 2020 berdasarkan Peraturan Menteri Negara Koperasi dan Usaha Kecil dan Menengah Republik Indonesia No.06/Per/M.KUKM/V/2006.

1. likuiditas koperasi selama empat tahun yang ditinjau dari Rasio Lancar (Current Ratio) dapat dinyatakan belum cukup likuid dalam memenuhi hutang jangka pendek dari aset lancar yang dimiliki koperasi.

2. Solvabilitas koperasi selama empat tahun yang ditinjau dari DtAR dapat dinyatakan bahwa total aset yang dimiliki koperasi kurang baik dalam memenuhi hutanghutangnya. Demikian solvabilitas koperasi selama empat tahun yang ditinjau dari $D t E R$ dapat dinyatakan bahwa modal sendiri yang dimiliki koperasi belum solvabel dalam memenuhi hutang jangka panjangnya.

3. Rasio Aktivitas Koperasi selama empat tahun yang ditinjau dari Receivable Turn Over nilai rasio ini memenuhi standar. Rasio Aktivitas Koperasi selama empat tahun yang ditinjau dari Asset Turn Over nilai rasio ini belum memenuhi standar.

4. Rentabilitas Koperasi selama empat tahun yang ditinjau dari Net Profit Margin (NPM) dapat dinyatakan cukup rentabel dalam menghasilkan laba (SHU). Rentabilitas Koperasi selama empat tahun yang ditinjau dari Return On Asset (ROA) dapat dinyatakan belum rentabel. Rentabilitas Koperasi selama 2017-2019 tahun yang ditinjau dari Return On Equity (ROE) dapat dinyatakan cukup rentabel dalam menghasilkan laba (SHU) dan pada tahun 2020 kurang rentabel dalam menghasilkan laba (SHU).

Kementerian Koperasi dan Usaha Kecil dan Menengah Republik Indonesia Nomor: 7/Per/Dep.6/IV/2016

1. Permodalan Koperasi selama empat tahun yang ditinjau dari Modal sendiri terhadap aset dinyatakan tingkat kesehatan tidak sehat. Permodalan Koperasi selama empat tahun yang ditinjau dari Rasio Kecukupan Modal (CAR) dinyatakan cukup sehat.

2. Efisiensi Koperasi selama empat tahun yang ditinjau dari aktiva tetap terhadap total aset dapat dinyatakan cukup baik. 
Vol 4 No 1 (2021) 52-62 P-ISSN 2620-295 E-ISSN 2747-0490 DOI: $1047467 /$ elmal.v4i1.522

3. Likuiditas Koperasi selama empat tahun yang ditinjau dari rasio kas dapat dinyatakan cukup likuid.

4. Kemandirian dan pertumbuhan selama empat tahun yang ditinjau dari rentabilitas aset dinyatakan dalam kategori rendah.

Saran dalam penelitian, penelitian ini mempunyai keterbatasan maka diharapkan untuk KSPPS Khairu Ummah sebaiknya lebih terbuka untuk masuk ke website KSPPS sendiri. penelitian selanjutnya agar dapat menambah variabel penelitian, sample penelitian dan waktu penelitian yang lebih lama sehingga bisa didapat sebuah analisis laporan keuangan yang lebih terperinci dan akurat.

\section{DAFTAR PUSTAKA}

Eindrias, T. D., \& Azizah, D. F. (2017). Analisa Tingkat Kesehatan Koperasi Simpan

Pinjam Berdasarkan Peraturan Nomor: 06/PER/DEP. 6/IV/2016 (Studi Pada Koperasi Simpan Pinjam Bahagia Kota Kediri). Jurnal Administrasi Bisnis, 51(2), 135140

Ghulam, Z. (2016). IMPLEMENTASI MAQASHID SYARIAH DALAM KOPERASI SYARIAH . Iqtishoduna.

Martono, N. (2011). Metode Penelitian Kuantitatif: Analisis Isi dan Analisis Data Sekunder. Jakarta: RajaGrafindo Persada .

Peraturan Menteri Koperasi dan UKM RI No.06/Per/M.KUKM/V/2006 tentang Pedoman Penilaian Koperasi Berprestasi.

Peraturan Deputi Bidang Pengawasan Kementerian Koperasi dan Usaha Kecil dan Menengah Republik Indonesia Nomor: 7 /Per/Dep.6/IV/2016 Tentang Pedoman Penilaian Kesehatan Koperasi Simpan Pinjam dan Pembiayaan Syariah dan Unit Simpan Pinjam dan Pembiayaan Syariah Koperasi.

Rhamadana, R. B. (2016). ANALISIS RASIO KEUANGAN UNTUK MENILAIN KINERJA KEUANGAN PADA PT. H.M SAMPOERNA Tbk. Jurnal Ilmu dan Riset Manajemen .

Sugiyono. (2014). Metode Penelitian Kuantitatif Kualitatif R\&D. Bandung: Alfabeta.

Suwarto. (2018). FINANCIAL RATIO ANALYSIS TO ASSESS FINANCIAL PERFORMANCE OF COOPERATIVES . Jurnal Fidusia.

Tolong, A., As, H., \& Rahayu, S. (2020). Analisis Kinerja Keuangan Koperasi

Simpan Pinjam Pada Koperasi Suka Damai. Jambura Economic Education Journal, 2(1), 25-33 